\title{
Power System Support Functions Provided by Smart Inverters-A Review
}

\author{
Xin Zhao, Liuchen Chang, Riming Shao, and Katelin Spence
}

\begin{abstract}
Renewable energy is seen as a viable alternative to traditional energy sources, and distributed generation (DG) based on renewable energy sources has experienced rapid growth worldwide. High penetration of renewable energy based DG systems makes the grid more vulnerable, and stricter standards have been issued for grid interconnection of DG systems. DG systems are expected to be controllable with high flexibility and reliability. Provision of grid support functions and ancillary services, such as reactive power control, fault ride-through and harmonic compensation, is the key to attaining higher utilization of DG. Such functionalities are implemented in new generation smart inverters, which can contribute to the reduced cost of energy and need for additional system resources. The state-of-the-art power system support functions are summarized in this paper for the purpose of enhancing operation in low-voltage networks. Experimental results are given to better understand the implementation of the functions.
\end{abstract}

Index Terms - Fault ride-through, harmonic compensation, power system support functions, reactive power control, smart inverters.

\section{INTRODUCTION}

$\mathrm{I}_{\mathrm{a}}^{\mathrm{N}}$ $\mathrm{N}$ recent years, there has been a rapid increase of renewable energy based distributed generation (DG) in power systems. These DG systems, such as photovoltaic (PV), wind, etc., have intermittent power output which disturbs the system operation [1], [2]. The penetration level of DG units is expected to further increase in the future. This is because they play an important role in reducing pollution, decreasing power transmission losses, and improving local utilization of renewable energy sources [3], [4].

However, intensely expanding installation of DG units into the grid also brings challenges to the distribution network, such as reverse power flow, voltage deviations, frequency fluctuations, and power quality problems [5]-[7]. The California Public Utilities Commission has initiated a Smart Inverter Working Group to investigate new requirements for inverter-based PV and energy storage systems. The recommendations have been approved to be included in California's Electric Tariff Rule 21, which governs DG interconnection in California utilities. Spurred by the CA Rule 21 update [8], UL released the latest 'Smart Inverter' standard for inverters (UL 1741SA) in September 2016 [9]. Meanwhile, a few IEEE and IEC standards are

Manuscript received March13, 2018.

The authors are with Emera and NB Power Research Centre for Smart Grid Technologies, University of New Brunswick, Fredericton, NB, Canada, E3B5A3 (xzhao8@unb.ca; lchang@unb.ca).

Digital Object Identifier 10.24295/CPSSTPEA.2018.00003 under revision or new development [10].

These new standards are published in order to regulate the interconnecting DG systems, especially in terms of power system support functions and ancillary services [8], [11]. These highly anticipated standards provide a certification method for smart inverter functionality and will help reduce barriers to large scaled renewable energy deployment. The functions should be developed to minimize the adverse effects from variable renewable energy generation and other grid disturbances [12].

Also, critical customer demands are continuously being updated to facilitate reliable and efficient power generation from DG units, which imposes more challenges for the interfaced inverters. Therefore, new generation smart inverters with enhanced control flexibility are desired to provide power system support functions [3].

Power system support functions from smart inverters such as reactive power compensation, fault ride-through, and power quality enhancement, together with higher reliability demands, are the key to further reducing the total cost of energy. This paper takes PV systems as an example to introduce, review and analyze the power system support functions of smart inverters.

The objective of this paper is to review the available technologies regarding power system support functions of smart inverters. The following sections in the paper describe the power system support functions in detail along with experimental results. The voltage support (reactive power control) function of smart inverters is described in Section II. Harmonic compensation is discussed in Section III. Voltage ride-through control strategy is introduced in Section IV, followed by frequency ride-through in Section V. Then, other power system support functions are introduced in Section VI. The final section gives the conclusion.

\section{Reactive Power Control}

Traditionally, PV systems are designed with active power control as governed by IEEE 1547 Standard for Interconnecting Distributed Resources with Electric Power Systems. However, the impact of increasing penetration of PV systems in low-voltage distribution networks may change the voltage profile of feeders. If the total installed PV is larger than the capacity of the host feeder, network safety and stability cannot be guaranteed. Specifically, when the production of a feeder surpasses its consumption, a reverse power flow occurs which leads to overvoltage and might cause problems to the coordination of protective devices and disconnection of equipment for stability reasons [13]. So the reactive power control strategy should be adopted to ensure the voltage is within the acceptable range.

Recently, interconnection standards issued in many coun- 


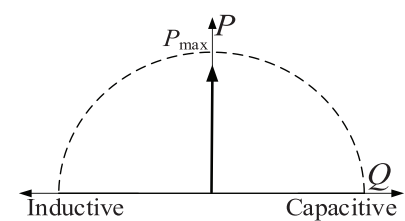

(a) Unity power factor method

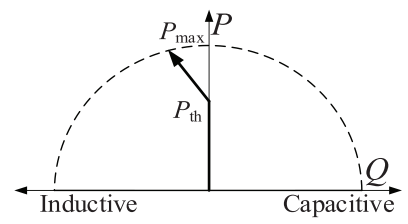

(b) Active power-dependent method
Fig. 1. Operational curve of inverter.

tries have specified reactive power control strategies in order to maintain power quality or provide ancillary services for the low-voltage networks. Therefore, the inverters should supply reactive power reasonably.

There are many papers focusing on reactive power control, and the control strategies are summarized in this section. Some commonly used reactive power control strategies included unity power factor method [14]-[16], active power-dependent method [16], [17], $Q(V)$ control [18], [19], $Q(V) / P(V)$ control [20], [21], 2-quadrant $P-Q$ planemethod [22]-[24], etc. A detailed analysis is shown as below.

\section{A. Unity Power Factor Method}

Previously, the most common reactive power control strategy was the unity power factor method [14]-[16], where the inverter operates with no injection of reactive power into the grid, as shown in Fig. 1(a). This approach is in complete compliance with the previous version of IEEE Standard 1547 and UL1741, which specifies that distributed resources shall not actively regulate voltage at the point of common coupling (PCC) [16], [25], [26].

However, the disadvantage of this method is that there will be overvoltage in the areas with high penetration levels of PV. In some applications, a limit on maximum active power generation is enforced to prevent voltage beyond the allowed range, and this will curtail the active power to the power system [27].

\section{B. Active Power-Dependent Method}

Utilities have succeeded in mitigating overvoltage problems due to unity power factor operation by slightly changing the power factor of the inverter. However, the reactive power control results in a considerable power loss to low-voltage grids. Hence, in order to minimize the power loss, the German Grid Codes proposed the standard characteristic curve in Fig. 1(b). The objective of the standard requires the generation unit to operate in reactive power consumption mode when the feed-in active power surpasses a threshold $P_{t h}$ in order to mitigate the overvoltage [28]. With the active power-dependent method [16], [17], the general relationship between active and reactive power of a PV system is defined as follows:

$$
\mathrm{Q}= \begin{cases}m\left(P-P_{t h}\right) & P>P_{t h} \\ 0 & P \leq P_{t h}\end{cases}
$$

where $m(<0)$ is a slope factor.

This method adjusts the reactive power flow back to the grid

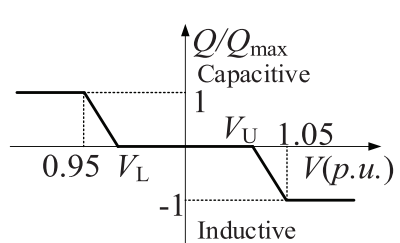

(a) $Q(V)$ control method

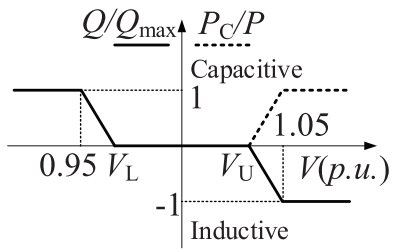

(b) $Q(V) / P(V)$ control method

Fig. 2. Schematic operational curve of PV inverter.

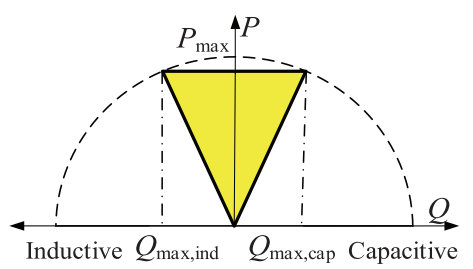

Fig. 3. 2-quadrant $P$ - $Q$ control method.

based on active power output of the inverter, thus providing a form of voltage regulation due to active power output variations. However, it does not actively regulate voltage at the PCC because the feeder impedance characteristics are not taken into account.

\section{C. $Q(V)$ Control}

The $Q(V)$ control method provides a dynamic voltage-regulation response based on local or area electrical power system voltage [18], [19]. One example of the $Q(V)$ characteristic curve is shown in Fig. 2(a). The inverter is either consuming or producing reactive power if its terminal voltage deviates from the predefined upper/lower critical voltages $V_{U}$ and $V_{L}$, respectively. Owing to the effect of feeder impedance, the voltage of PV inverters near the feeder typically are within the range, so these inverters do not contribute in voltage regulation. But inverters near the end of the feeder need to provide reactive power, causing additional stress on these inverters.

\section{D. $Q(V) / P(V)$ Control}

The $Q(V) / P(V)$ strategy has been proposed in order to further mitigate overvoltage when $Q(V)$ control alone is inefficient. One example of the $Q(V) / P(V)$ characteristic curve is shown in Fig. 2(b). The control strategy is similar to the $Q(V)$ method with the addition of an active power curtailment $\left(P_{C}\right)$ feature [20], [21].

\section{E. 2-Quadrant P-Q Control}

Fig. 3 illustrates inverter operation in a 2-quadrant $P-Q$ plane, where the inverter can generate either inductive or capacitive reactive power at different voltage levels [22]-[24]. The feasible operating space is enclosed by the triangular-shaded area that represents the total power factor limit and inverter rating curve. The inverter generates inductive reactive power when the voltage exceeds the upper voltage level, and the inverter generates 


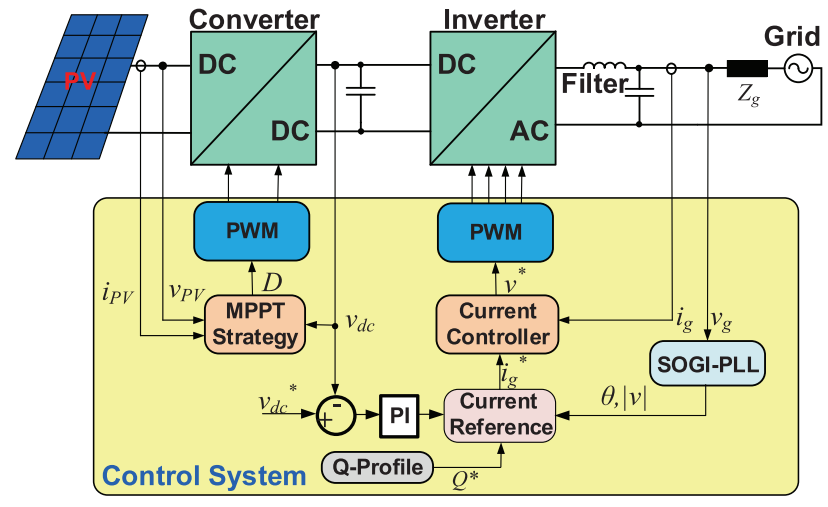

Fig. 4. Schematic diagram of single-phase grid-connected PV system.

capacitive reactive power when the voltage is below the lower voltage level.

There is room for most PV inverters to provide reactive power compensation, since the PV inverters rarely operate at the rated power levels. The maximum available reactive power $\left|Q_{\max }\right|$ can be determined by:

$$
\left|Q_{\max }\right|=\sqrt{S_{\max }^{2}-P_{\text {ins }}^{2}}
$$

where $P_{\text {ins }}$ is the instantaneous active power and $S_{\max }$ is the maximum apparent power.

\section{F. Reactive Power Control at Night}

Being weather-dependent, active power injection from PV inverters is only possible when there is sufficient solar irradiance. Consequently, while active power is not available during nights, reactive power can be delivered to the grid. That is to say, the PV systems can work as a static Var generator (SVG) and provide dynamic compensation of reactive power to adjust the grid voltage of the power system. This operation mode is referred to as reactive power control at night [3], [29].

Considering the reactive power constraint of a PV inverter shown in (2), the PV inverter can inject reactive power equivalent to the maximum apparent power during the night. The suitable reactive power value is decided by the real-time grid voltage level.

\section{G. Test Results of Reactive Power Control}

Residential PV installations are very common and single-phase inverter is required for a PV system connecting to the grid. Fig. 4 shows the schematic diagram of a typical single-phase grid-connected PV system. The two-stage converter is adopted to achieve power conversion, which can achieve a flexible control strategy. The DC/DC converter is adopted to offer maximum power point tracking (MPPT) of PV output and boost the PV panel voltage to an acceptable range for the DC/ $\mathrm{AC}$ converter (i.e. inverter). The inverter stabilizes the DC-link voltage and controls the grid current with good power quality. In this control system, the reference reactive power $Q^{*}$ is generated according to the aforementioned reactive power control

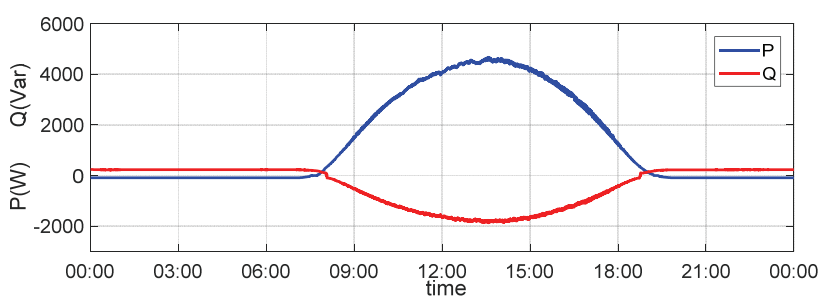

(a) Constant power factor (CPF) control

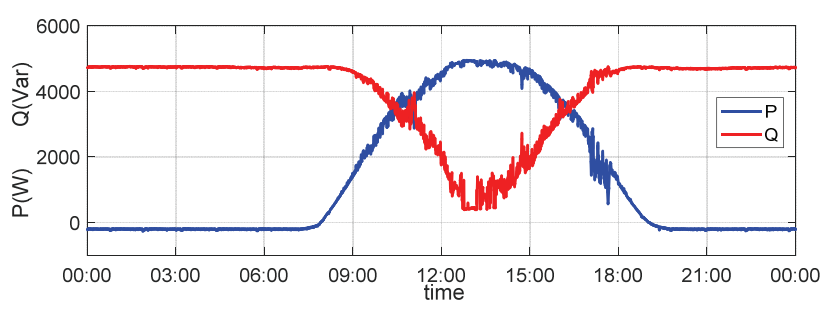

(b) Constant apparent power (CAP) control

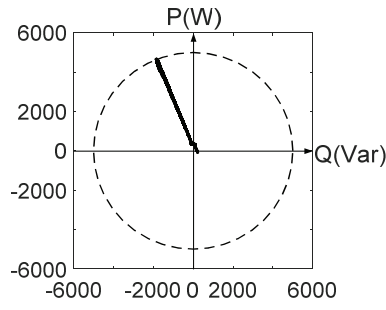

(c) CPF-P\&Q result

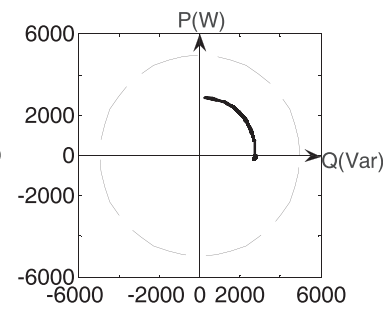

(d) CAP-P\&Q result
Fig. 5. Test results of reactive power control.

strategies.

Two different control objectives are tested based on an actual $5 \mathrm{~kW}$ single-phase PV system (parameters are in Appendix), and the $24 \mathrm{hr}$ operational results are shown in Fig. 5. Fig. 5(a) and Fig. 5(c) show that the reactive power varies with active power, while the power factor keeps constant based on constant power factor control strategy, taking no consideration of power loss and AC filter capacitor. In Fig. 5(b) and Fig. 5(d), the apparent power keeps constant all the time and the PV inverter provides reactive power equivalent to the maximum apparent power during the night if needed.

\section{HARMONIC COMPENSATION}

Nowadays, many power converter based apparatuses such as variable speed drives and switching mode power supplies, have been used. These loads have created issues in power quality [30]-[32].

For grid-connected generation systems, the current distortion is an important power quality index. For instance, both IEEE Standard 1547 and Rule 21 state that the total harmonic distortion (THD) of grid current injection into distribution system at the PCC should not exceed 5\% at the rated current level. However, grid conditions and operational modes may significantly impact the distortion level of the injected current from grid-connected inverter systems. Therefore, a high-performance 
control solution must be developed for grid-connected systems to produce high-quality power in different operation conditions.

To compensate harmonic distortions in distribution systems, many active and passive filtering methods have been developed [33]. However, installing additional filters is not very favorable due to their high costs and sensitivity to parameter variations. Alternatively, flexible control of grid-connected inverters may be utilized to offer the possibility of power quality improvement. Consequently, the harmonic compensation function could be integrated with the primary power generation by modifying the control strategies [34]-[36]. This is especially attractive considering that PV systems do not always operate at full capacity, and the available capacity can be used to realize harmonic compensation without additional costs [37].

For PV systems participating in power quality enhancement, there are three harmonic compensation objectives in general: 1) PV current harmonic rejection, 2) PCC current harmonic compensation, and 3) PCC voltage harmonic compensation [38]. The first and second objectives can be attained by modifying the current controller of the inverter. Voltage control is essential for achieving the third objective, and virtual impedance is always introduced to accomplish the compensation.

\section{A. Controller Based Methods}

There has been significant work done in the area of harmonic compensation using different controllers. Multi-resonant controller (MRC) plugged into proportional-resonant/proportional-integral (PR/PI) controller are the most popular controller for harmonic elimination, which can easily compensate low-order harmonics [39]-[43]. However, the discretization of multiple resonant controllers will result in a heavy computation burden, and the fundamental frequency variation will affect the performance. Also, as mentioned in [42], the phase margin of the system becomes small with MRC and resonances may be triggered if phase-lead compensators are improperly designed.

The study in [44]-[47] considers the use of repetitive controller $(\mathrm{RC})$ based harmonic elimination, and $\mathrm{RC}$ with a simple phase compensator can track or reject all harmonics below the Nyquist frequency. It can eliminate harmonics using much less computation than MRC does, but the dynamic response is much slower than MRC's. Also, it is impossible for RC systems to optimize the error convergence rate, since the gain of all the harmonics in $\mathrm{RC}$ are equal.

Predictive controller (PC) was known as the deadbeat controller with a high bandwidth and fast dynamic response, which is widely used for current error compensation to offer high quality current to the grid [48]. However, it suffers degraded performance due to the time-delay and system model mismatch [49]. Several methods have been proposed to improve the overall performance of PC. Improved algorithms have been presented to reduce the sensitivity to parameter variations [50]-[52], compensating for the time delay [53], [54] and rejecting disturbances experienced by the control system [55], [56].

A hybrid controller by combining the RC and PR controller is also developed, and it can achieve high-performance regardless of the operational modes [57], [58].

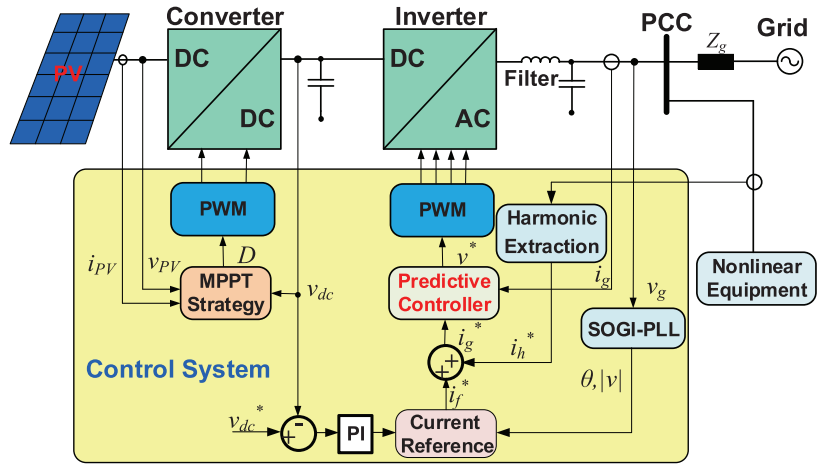

Fig. 6. Control structure of PV systems for harmonic compensation.

\section{B. Virtual Impedence Based Methods}

Over time, the virtual impedance concept is increasingly employed for the control of power electronic systems, which is developed to optimize inductance-to-resistance $(\mathrm{X} / \mathrm{R})$ ratio of the inverter's equivalent output impedance [59]. Generally, the virtual impedance loop can either be embedded as an additional degree of freedom for active stabilization and disturbance rejection, or be employed as a command reference generator for the inverters to provide ancillary services. The virtual impedance is generally implemented based on the feedback of output filter states and/or the feedforward of the disturbance variables. By shaping the control output impedance, the virtual impedance can be used for harmonic compensation [60].

The virtual impedances at the harmonic frequencies can be implemented in different ways. The research in [61]-[63] considers the inverter as a small resistance at harmonic frequencies, where the PCC voltage is measured and the harmonic components are extracted to produce the reference harmonic current of the inverter. A virtual impedance across the grid side inductance, which can be represented by a series $R L$ branch in parallel with a negative inductance, is added through the grid current feedback control [64]. A virtual $R C$ damper in parallel with the passive filter capacitor is proposed in [65], where the positive resistance achieves better performance of harmonic resonance damping, and the negative inductance reduces the grid side inductor for the purpose of better harmonic distortion mitigation. In order to eliminate the influence of the virtual impedance on the power control, a high-pass filter is introduced in the virtual impedance control and the virtual impedance is only effective in the high resonance frequency range [66].

\section{Test Results of Harmonic Compensation}

The schematic diagram of PV system with harmonic compensation is shown in Fig. 6. The predictive controller based method is adopted to achieve the PCC current harmonic elimination.

The experimental results in Fig. 7(a) shows that the current at PCC is distorted by nonlinear equipment. After adding the PV system to provide harmonic compensation, the current at PCC becomes much more sinusoidal in Fig. 7(b) and the THD of current decreases to $8.01 \%$ from $41.21 \%$ in Fig. 7 (a). 


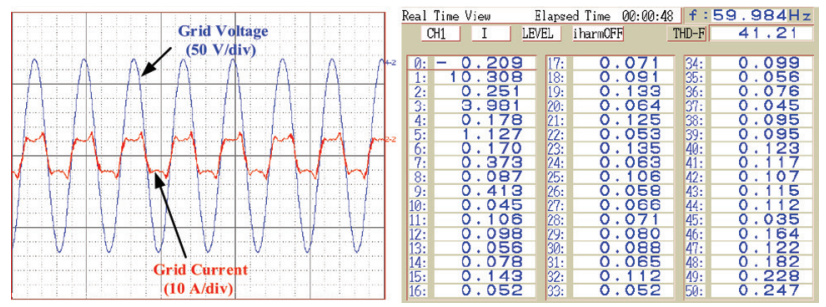

(a) PCC current waveform and harmonics, without compensation

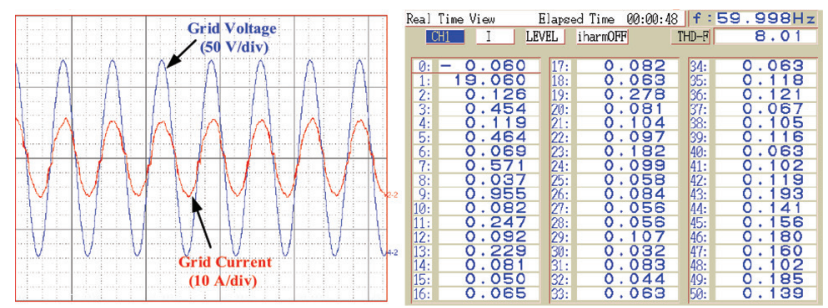

(b) PCC current waveform and harmonics, with compensation

Fig. 7. Test results of PV systems for harmonic compensation.

\section{Voltage Ride-Through}

Recently, with high levels of penetration of PV generation, maintaining the grid stability represents a greater challenge to the network operators. The events of voltage sags happening every year in many countries have increased. Utilities have released grid codes that require these systems to provide grid support during grid faults. One of them is to introduce the voltage ride-through (VRT) capability into PV systems. To fulfill these grid codes, the PV systems need to satisfy the VRT capability requirement and contribute to stabilizing the grid voltage during a disturbance [67], [68].

Several countries have updated the grid codes for VRT in low/medium-voltage systems. For instance, CA Rule 21 allows PV inverters to ride through faults. The low/high voltage ridethrough (L/HVRT) function is a departure from the previous UL 1741/IEEE 1547 standards where only must trip levels and durations were assessed. Now smart inverters must stay connected to the grid for a specific duration and then trip after the must trip time, as shown in Fig. 8 [8], [12].

Along with the updates of grid codes, the control techniques of PV inverters are required to be upgraded as well, because the operation during voltage faults is much different from that of normal conditions. Some issues need to be considered, such as fault detection and the power balance control under different voltage levels. In order to successfully complete the VRT operation, several key technologies should be resolved including voltage detection techniques and power control strategies.

\section{A. Voltage Detection Methods}

The voltage detection and synchronization scheme play a major role in the control of PV systems under grid faults. A good synchronization system should respond to a voltage change immediately when a fault occurs. Many methods can obtain the exact voltage dip depth and phase angle within one fundamental period under ideal operation conditions. However these meth-

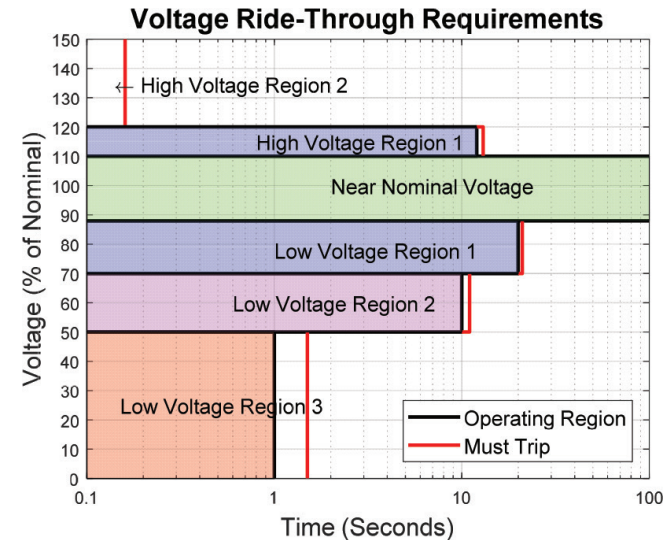

Fig. 8. Voltage ride-through regions according to Rule 21.

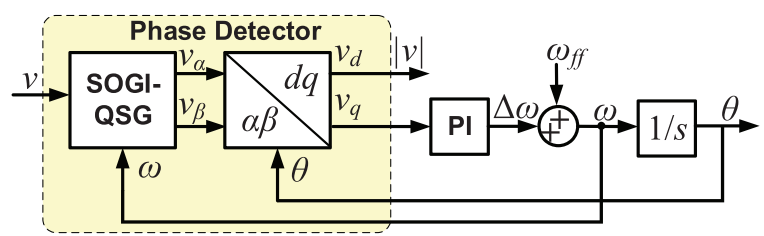

Fig. 9. The structure of SOGI-PLL.

ods are incapable of coping with harmonics and unbalanced grid conditions. Nowadays, phase-locked loop (PLL) technique based synchronization methods have become the most widely used solutions. Some methods have been proposed to enhance the performance under polluted grid conditions.

Two widely-used PLLs, the enhanced PLL (EPLL) [69][71] and the second-order generalized integrator (SOGI)-based PLL (SOGI-PLL) [72]-[74], are based on the combinations of adaptive filters with a sinusoidal multiplier and a quadrature signal generator system. These PLLs can only filter high frequency harmonics; however, the low frequency harmonics are not eliminated.

Recently, more advanced PLL techniques have been presented, which enable robustness of synchronization against both the low and high order harmonics. A PLL based on a multi harmonic decoupling cell (MHDC) technique scheme is proposed [75], [76], which can achieve an accurate performance under harmonic distortions. However, it increases the complexity resulting in heavy computation. To eliminate the DC offset and harmonics of SOGI-PLL under grid faults, several methods have been proposed in the literature [77]-[81]. A new second-order SOGI-QSG (SO-SOGI-QSG) presented [81] inherits the simplicity of the SOGI-QSG and also has better disturbance attenuation.

Reference [82] has compared several widely-used PLL methods in terms of accuracy and dynamic response during voltage faults, and it reveals that the SOGI-PLL is a promising synchronization technique in single-phase grid-connected systems for VRT. Therefore, the SOGI-PLL has been adopted to detect both phase and magnitude of grid voltage in single-phase PV systems, and the structure of SOGI-PLL is shown in Fig. 9.

\section{B. Control Strategies}

The control diagram of the PV system with VRT capability 


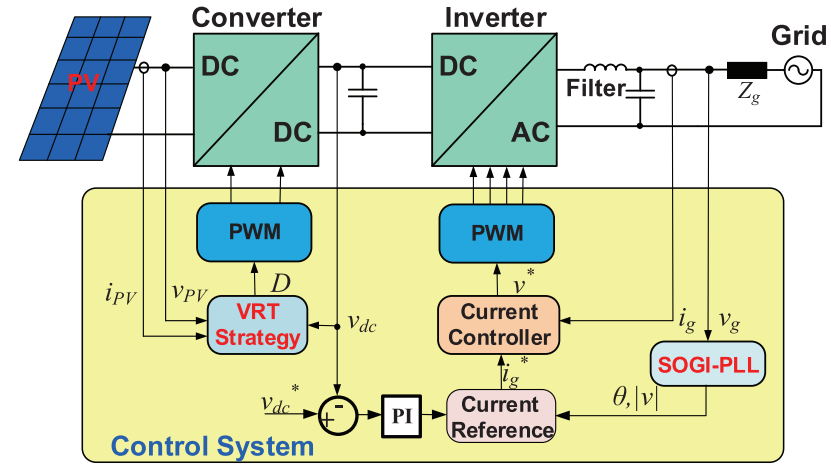

Fig. 10. Control diagram of PV system with VRT capability.

is shown in Fig. 10. The SOGI-PLL is used to detect both the phase and amplitude of the grid voltage quickly during a voltage fault. However, the control strategy should be modified during a voltage fault to satisfy the grid codes.

Some methods have been proposed to achieve better performance under grid voltage faults. The maximum current amplitude control for the inverter is presented [83], [84] to provide the maximum reactive power under the allowable current amplitude. Different reactive power injection strategies are proposed to improve the reliability [85], including constant average active power control, constant active current control, constant peak current control, and thermal optimized reactive power control strategy. To improve the output waveform quality and maintain safe operation by attenuating double-line-frequency voltage ripple during a grid voltage drop, a DC-link voltage adjustment method for the inverter is proposed [86]. The concept of multi-mode operation for PV power systems is presented to maintain balanced power [87]. According to the new standard Rule 21, the control strategies of PV system is given as below.

\section{1) MPPT Mode}

The converter should be in continuous operation when the grid voltage is in the "Near Nominal Voltage" region in Fig. 8, so the DC/DC converter should remain in its MPPT mode to harvest the maximum power from the PV array.

\section{2) Constant Power Control Mode}

If the grid voltage is in Low Voltage Regions 1 \& 2 defined in Fig. 8, the present active output power and current of the single-phase inverter may be higher than the allowable maximum value. So the MPPT function of the boost converter should be abandoned, and the simplest way is to turn off the switches of the boost converter. However, in order to continuously deliver the solar energy to the grid and to shorten the MPPT response time after the grid fault is cleared, the constant power control mode should be adopted.

\section{3) Momentary Cessation Mode}

If the grid voltage is in Low Voltage Region 3 or High Voltage Region 1, the PV system shall work in momentary cessation mode and cease to energize in not more than $0.16 \mathrm{~s}$ but not trip. Therefore, the switches of the boost converter and single-phase
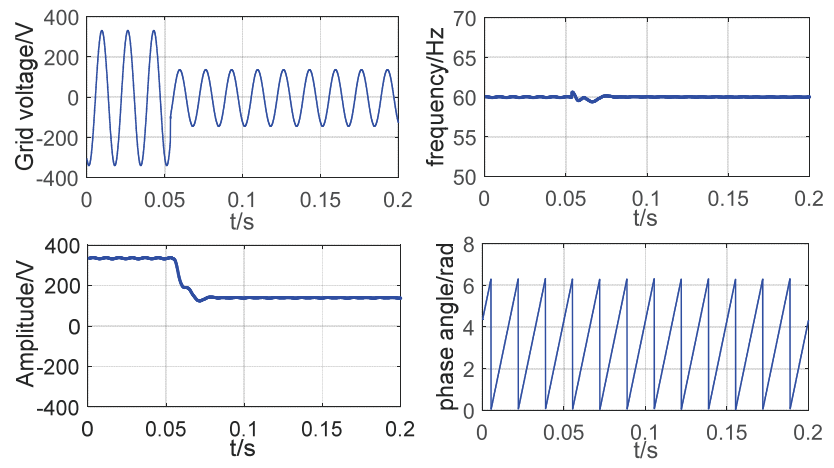

Fig. 11. Experimental result of SOGI-PLL under grid voltage dip.

inverter should be turned off but the breakers and contactors of the PV system should keep closed.

\section{Test Results of Voltage Ride-Through}

A grid simulator (California Instruments MX22.5) is adopted to generate grid voltage faults, and experimental results of the $5 \mathrm{~kW}$ single-phase PV system are given to validate the performance of the synchronization technique and the voltage ridethrough control strategy.

\section{1) PLL Results}

The amplitude step of grid voltage is generated by the grid simulator to simulate a grid voltage dip fault from $240 \mathrm{~V}$ to $100 \mathrm{~V}$, shown in Fig. 11. The experimental results show that the SOGIPLL can detect the voltage amplitude and phase angle precisely in different voltage levels and has a good dynamic response to amplitude changes. The settling time of the amplitude is about 1 grid cycle. The frequency and phase angle are not affected significantly when the voltage dips.

\section{2) VRT Results}

The performance of VRT is evaluated experimentally, and different scenarios are implemented to test the multi-mode operation of PV systems mentioned before.

When the grid voltage dips to $63 \%$ of its normal value shown in Fig. 12, the voltage is in Low Voltage Region 2 according to Rule 21. So the PV system should be in mandatory operation and the control mode of converter should change from the MPPT mode to the constant power control mode. The PV system can keep the connection and deliver power to the grid during voltage dips, and there is no overcurrent and overvoltage. The inverter returns to the MPPT mode after the voltage recovers.

When the grid voltage dips to $42 \%$ of its normal value shown in Fig. 13, the voltage is in Low Voltage Region 3 according to Rule 21 . So the PV system should work in momentary cessation, and the control mode of the converter should change from the MPPT mode to the momentary cessation mode. The PV system still keeps the connection with the grid but ceases to energize in $30 \mathrm{~ms}$ after the voltage dips. The system starts delivering power to the grid when the voltage recovers to normal. 


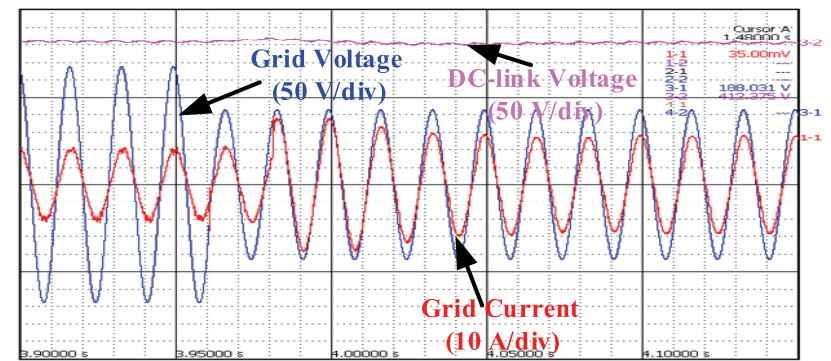

(a) Voltage dips

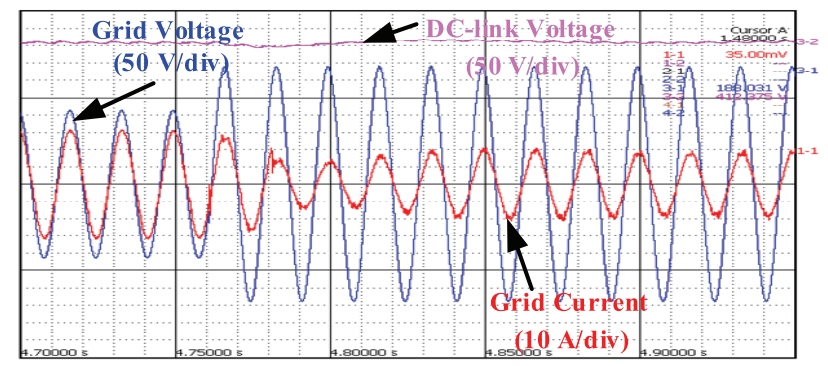

(b) Voltage recovers

Fig. 12. Experimental results of PV system when voltage dips to $63 \%$.

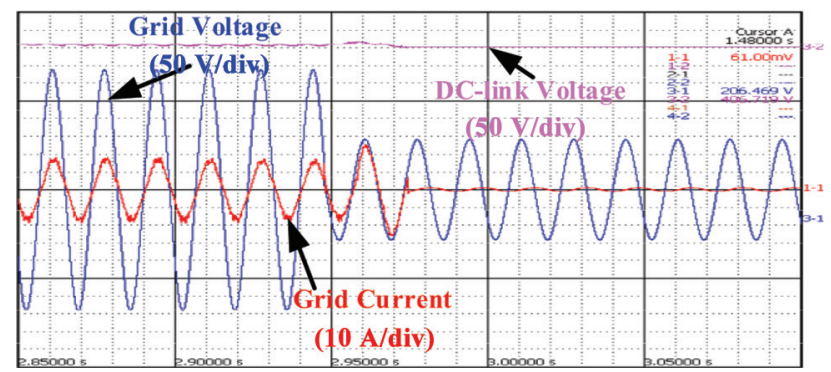

(a) Voltage dips

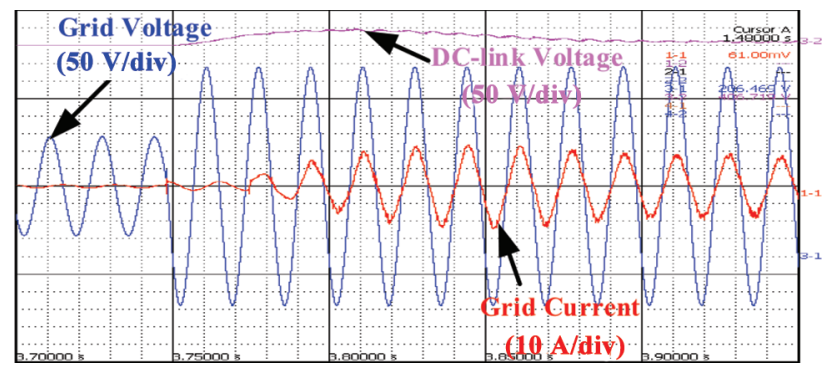

(b) Voltage recovers

Fig. 13. Experimental results of PV system when voltage dips to $42 \%$.

\section{FreQuency Ride-Through}

\section{A. Introduction}

The frequency ride-through (FRT) regions corresponding to Rule 21 are shown in Fig. 14. Smart inverter systems shall remain connected to the power system while the grid is within the "must stay connected frequency-time region", and shall disconnect from the grid outside the frequency-time range.

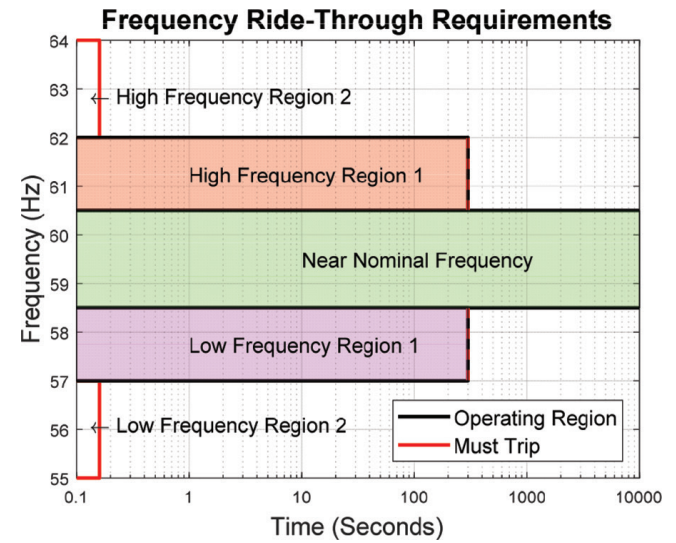

Fig. 14. Frequency ride-through regions according to Rule 21.
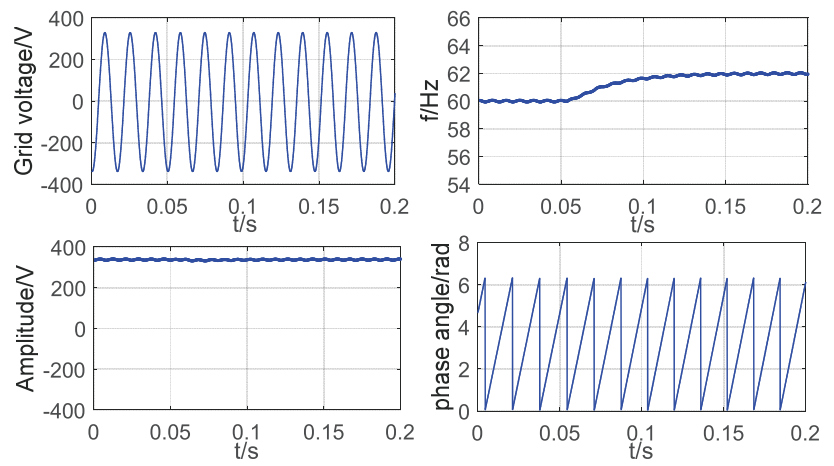

Fig. 15. Experimental result of SOGI-PLL under grid frequency swell.

The high and low frequency protection limits will permit generation systems to ride through temporary frequency rises and dips, thus decreasing the number of unnecessary disconnections by generation systems and possible power outages. Generation systems will no longer disconnect before the frequency levels have had time to possibly recover and return within their normal limits [11].

FRT is easy to implement comparing with VRT, because there is no overcurrent or overvoltage and the control strategy remains unchanged for PV systems during the transition process. The most important issue for FRT is the frequency detection technique, which should be able to detect the frequency accurately with a good dynamic response. Similar to the voltage detection in VRT, a PLL is employed to obtain the frequency, such as the SOGI-PLL.

\section{B. Test Results of Frequency Ride-Through}

The grid simulator is adopted to generate grid frequency faults, and experimental results of a single-phase PV system are given to verify the FRT capability of the $5 \mathrm{~kW}$ PV inverter.

\section{1) Frequency Detection Results}

Experimental results of a grid frequency step change from $60 \mathrm{~Hz}$ to $62 \mathrm{~Hz}$ are shown in Fig. 15. It validates the frequency-adaptive characteristic of the SOGI-PLL which is able to overcome a big jump of frequency without oscillations. The system has a good dynamic response under frequency changes, 


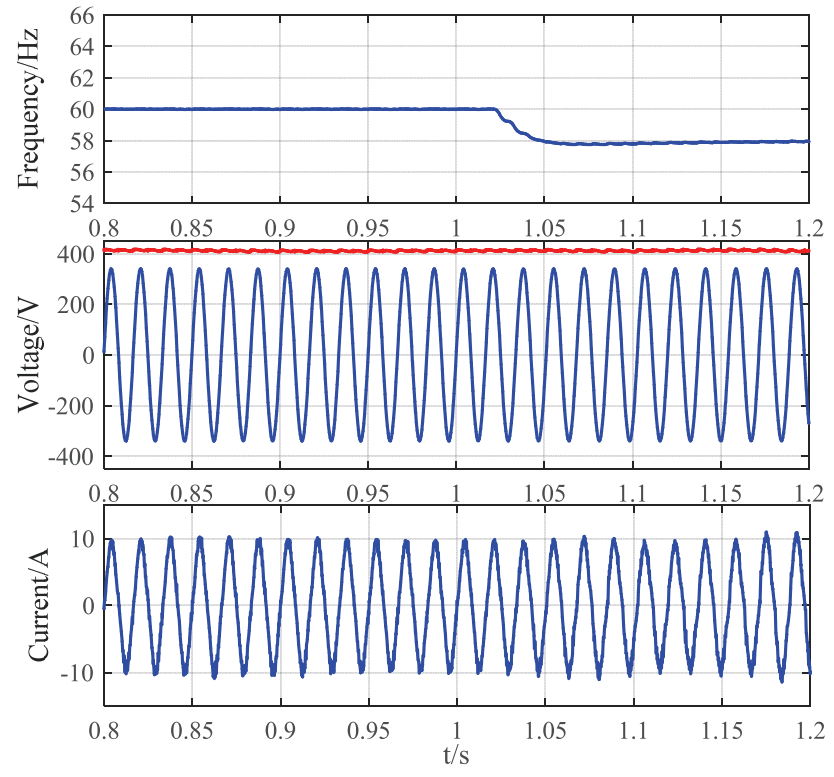

Fig. 16. Experimental result of PV system when frequency dips to $58 \mathrm{~Hz}$.

and the settling time of the frequency is about 3-4 grid cycles. The amplitude is not affected significantly when the frequency swells.

\section{2) FRT Results}

Various tests of FRT in different frequency regions have been implemented experimentally, and two scenarios are shown below.

When the grid frequency dips to $58 \mathrm{~Hz}$ as shown in Fig. 16, which is in Low Frequency Region 1 according to Rule 21, the PV system should be in mandatory operation. From the result, the PV system can deliver power to the grid during the frequency dip, without overcurrent and overvoltage.

When grid frequency swells to $63 \mathrm{~Hz}$ as shown in Fig. 17, which is in High Frequency Region 2 according to Rule 21, the PV system should trip within $0.16 \mathrm{~s}$. The PV system trips in about 50ms after frequency swells, as seen from Fig. 17, satisfying the requirement of the standard.

\section{Other Power System Support Functions}

In addition to the aforementioned power system support functions of smart inverters, others functions are mentioned in the interconnection standards. The following gives a brief introduction to some of them.

\section{A. Freq/Watt Control}

Freq/Watt control is required in DG units in many European countries and is also included as an optional function in Rule 21.

In order to provide frequency support to the grid, an inverter may change its active power output with the changes in grid frequency. As frequency increases, the desired response of the inverter is to decrease its active power output. Contrariwise, as frequency decreases it is desired for the inverter to increase its
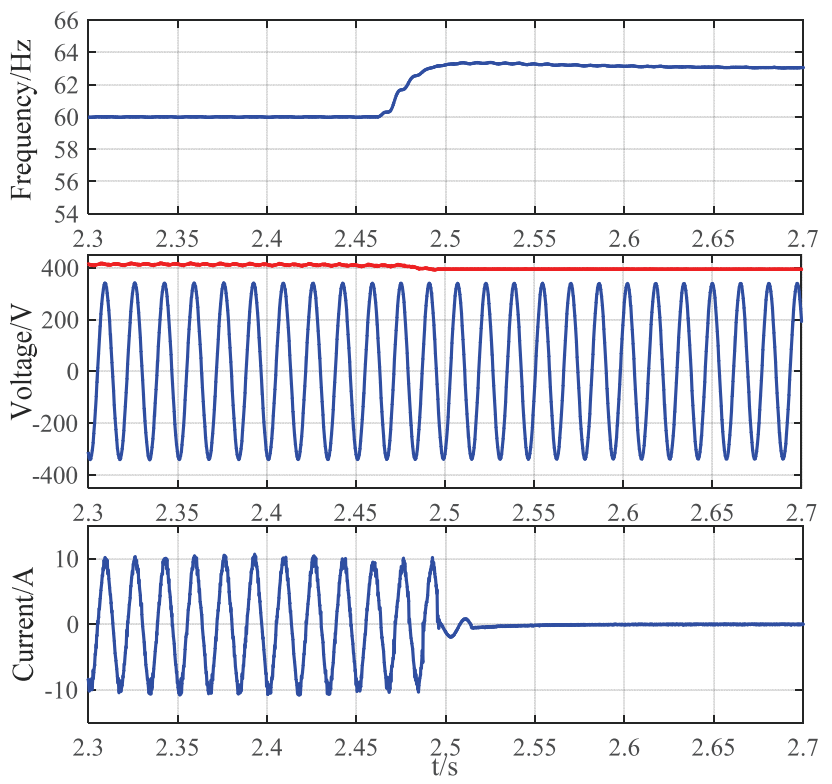

Fig. 17. Experimental result of PV system when frequency swells to $63 \mathrm{~Hz}$.

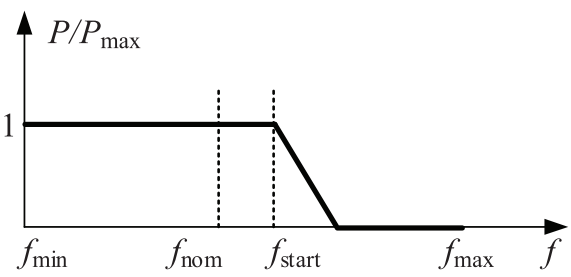

Fig. 18. Characteristic of Freq/Watt control.

active power output [11].

For PV systems, inverters only export no more than the maximum power of the PV panels to the grid. Such inverters may not be capable of increasing their active power and so can only provide an over frequency response. This active power response to a change in frequency is referred to as a Freq-Watt droop function, and the characteristic of Freq/Watt control is shown in Fig. 18.

\section{B. Black Start}

Black start capability refers to power system restoration after a power outage on the grid. Research on black start is mainly focused on the restoration of traditional power systems, high voltage direct current (HVDC) systems and microgrid systems. Black start capability is also an optional function according to Rule 21. An inverter-based distributed generation system may operate in a microgrid (possibly just itself) and support additional loads being added, so long as they are within its generation capability [11].

For inverter based systems under such a scenario, an inverter should operate in voltage control mode to generate a stable and clean reference voltage in the absence of the main grid voltage, and facilitate grid synchronization to smoothly switchover from the islanded operation to grid-connected operation when the main grid is restored. 


\section{CONCLUSION}

The concept of smart inverters has been emphasized in newly developed DG interconnection standards in order to achieve smooth and grid-friendly integration of large-scale PV systems, and of renewal energy systems in general. Smart inverters could provide a suite of power system support functions. This paper reviews the state-of-the-art power system support functions of smart inverters, such as reactive control, fault ride-through, and harmonic compensation, which could be an enhancement for the new PV inverters to offer additional system resources for grid operation. Viable methods to implement these functions are investigated and tested in a single-phase PV system developed by the authors. Experimental results have demonstrated that smart inverters with power system support functions can provide system resources to alleviate issues created by high PV penetration into the grids.

APPENDIX

Parameters of Single-Phase PV System Developed by Authors

\begin{tabular}{cccc}
\hline \hline Parameter & Value & Parameter & Value \\
\hline Power rating & $5 \mathrm{~kW}$ & Grid voltage & $240 \mathrm{~V} / 60 \mathrm{~Hz}$ \\
AC filter inductor & $1.6 \mathrm{mH}$ & ACfilter capacitor & $10 \mu \mathrm{F}$ \\
DC-Link capacitor & $2050 \mu \mathrm{F}$ & Boost inductor & $0.19 \mathrm{mH}$ \\
Switching frequency & $10 \mathrm{kHz}$ & & \\
\hline \hline
\end{tabular}

\section{REFERENCES}

[1] R. H. Lasseter, "Smart distribution: Coupled microgrids," Proc. IEEE, vol. 99, no. 6, pp. 1074-1082, 2011.

[2] F. Blaabjerg, Z. Chen, and S. B. Kjaer, "Power electronics as efficient interface in dispersed power generation systems," IEEE Trans. Power Electron., vol. 19, no. 5, pp. 1184-1194, 2004.

[3] Y. Yang, F. Blaabjerg, H. Wang, and M. G. Simões, "Power control flexibilities for grid-connected multi-functional photovoltaic inverters," IET Renew. Power Gener, vol. 10, no. 4, pp. 504-513, 2016.

[4] Y. Han, H. Li, P. Shen, E. A. A. Coelho, and J. M. Guerrero, "Review of active and reactive power sharing strategies in hierarchical controlled microgrids," IEEE Trans. Power Electron., vol. 32, no. 3, pp. 2427-2451, 2017.

[5] E. Paal and Z. Tatai, "Grid connected inverters influence on power quality of smart grid," Power Electron. Motion Control, pp. 35-39, 2010.

[6] B. I. Craciun, T. Kerekes, D. Sera, and R. Teodorescu, "Frequency support functions in large PV power plants with active power reserves," IEEE J. Emerg. Sel. Top. Power Electron., vol. 2, no. 4, pp. 849-858, 2014.

[7] E. J. Coster, J. M. A. Myrzik, B. Kruimer, and W. L. Kling, "Integration issues of distributed generation in distribution grids," Proc. IEEE, vol. 99, no. 1, pp. 28-39, 2011.

[8] California Public Utilities Commission, "ELECTRIC RULE NO. 21," 2016.

[9] Underwriters Laboratories 1741 Ed. 2, "Inverters, converters, controllers and interconnection system equipment for use with distributed energy resources," 2016.

[10] Y. Xue and J. M. Guerrero, "Smart inverters for utility and industry applications," PCIM Eur. 2015; Int. Exhib. Conf. Power Electron. Intell. Motion, Renew. Energy Energy Manag. Proc., no. May, pp. 1-9, 2015.

[11] Smart Inverter Working Group Recommendations, "Recommenda- tions for updating the technical requirements for inverters in distributed energy resources," 2014

[12] S. Gonzalez, J. Johnson, M. J. Reno, and T. Zgonena, "Small commercial inverter laboratory evaluations of UL 1741 SA grid-support function response times," Conf. Rec. IEEE Photovolt. Spec. Conf., vol. 2016-Novem, pp. 1790-1795, 2016.

[13] M. Hasheminamin, V. G. Agelidis, V. Salehi, R. Teodorescu, and B. Hredzak, "Index-based assessment of voltage rise and reverse power flow phenomena in a distribution feeder under high pv penetration," IEEE J. Photovoltaics, vol. 5, no. 4, pp. 1158-168, Jul. 2015.

[14] E. A. Man, "Control of grid connected PV systems with grid support functions," 2012.

[15] E. Demirok, P. C. González, K. H. B. Frederiksen, D. Sera, P. Rodriguez, and R. Teodorescu, "Local reactive power control methods for overvoltage prevention of distributed solar inverters in low-voltage grids," IEEE J. Photovoltaics, vol. 1, no. 2, pp. 174-182, 2011.

[16] J. W. Smith, W. Sunderman, R. Dugan, and B. Seal, "Smart inverter volt/var control functions for high penetration of $\mathrm{PV}$ on distribution systems," 2011 IEEE/PES Power Syst. Conf. Expo. PSCE 2011, pp. 1-6, 2011.

[17] M. J. E. Alam, K. M. Muttaqi, and D. Sutanto, "A multi-mode control strategy for VAr support by solar PV inverters in distribution networks," IEEE Trans. Power Syst., vol. 30, no. 3, pp. 1316-326, 2015.

[18] P. Jahangiri and D. C. Aliprantis, "Distributed Volt/VAr control by PV inverters," IEEE Trans. Power Syst., vol. 28, no. 3, pp. 3429-439, 2013.

[19] J. Seuss, M. J. Reno, R. J. Broderick, and S. Grijalva, "Improving distribution network PV hosting capacity via smart inverter reactive power support," IEEE Power Energy Soc. Gen. Meet., vol. 2015-Septe, no. 1, pp. 0-4 2015.

[20] T. Stetz, K. Diwold, M. Kraiczy, D. Geibel, S. Schmidt, and M. Braun, "Techno-economic assessment of voltage control strategies in low voltage grids," IEEE Trans. Smart Grid, vol. 5, no. 4, pp. 2125$132,2014$.

[21] T. Stetz, "Autonomous voltage control strategies in distribution grids with photovoltaic systems: Technical and economic assessment," 2014.

[22] A. R. Malekpour and A. Pahwa, "A Dynamic operational scheme for residential pv smart inverters," IEEE Trans. Smart Grid, pp. 1-10, 2016.

[23] Y. Bae, T. K. Vu, and R. Y. Kim, "Implemental control strategy for grid stabilization of grid-connected PV system based on German grid code in symmetrical low-to-medium voltage network," IEEE Trans. Energy Convers., vol. 28, no. 3, pp. 619-631, 2013.

[24] F. Olivier, P. Aristidou, D. Ernst, and T. Van Cutsem, "Active management of low-voltage networks for mitigating overvoltages due to photovoltaic units," IEEE Trans. Smart Grid, vol. 7, no. 2, pp. 926936, 2016.

[25] A. R. Malekpour and A. Pahwa, "A Dynamic operational scheme for residential pv smart inverters," IEEE Trans. Smart Grid, vol. PP, no. 99, pp. 1-10, 2016.

[26] "IEEE standard for interconnecting distributed resources with electric power systems," IEEE Std 1547-2003, pp. 1-28, Jul. 2003.

[27] T. Stetz, F. Marten, and M. Braun, "Improved Low Voltage Grid-Integration of Photovoltaic Systems in Germany," IEEE Trans. Sustain. Energy, vol. 4, no. 2, pp. 534-542, Apr. 2013.

[28] A. Samadi, R. Eriksson, L. Söder, B. G. Rawn, and J. C. Boemer, "Coordinated active power-dependent voltage regulation in distribution grids with pv systems," IEEE Trans. Power Deliv., vol. 29, no. 3, pp. 1454-1464, Jun. 2014.

[29] A. Anurag, Y. Yang, and F. Blaabjerg, "Thermal performance and reliability analysis of single-phase PV inverters with reactive power injection outside feed-in operating hours," IEEE J. Emerg. Sel. Top. Power Electron., vol. 3, no. 4, pp. 870-880, 2015.

[30] D. G. Infield, P. Onions, A. D. Simmons, and G. A. Smith, "Power quality from multiple grid-connected single-phase inverters," IEEE Trans. Power Deliv., vol. 19, no. 4, pp. 1983-1989, 2004.

[31] P. González, E. Romero, V. M. Miñambres, M. A. Guerrero, and E. González, "Grid-connected PV plants. Power quality and technical requirements," 9th Int. 2014 Electr. Power Qual. Supply Reliab. Conf. PQ 2014 - Proc., pp. 169-176, 2014. 
[32] P. Acuna, L. Moran, M. Rivera, J. Dixon, and J. Rodriguez, "Improved active power filter performance for renewable power generation systems," IEEE Trans. Power Electron., vol. 29, no. 2, pp. 687-694, 2014.

[33] L. Asiminoaei, F. Blaabjerg, S. Hansen, and P. Thøgersen, "Adaptive compensation of reactive power with shunt active power filters," IEEE Trans. Ind. Appl., vol. 44, no. 3, pp. 867-877, 2008.

[34] M. Cirrincione, M. Pucci, and G. Vitale, "A single-phase dc generation unit with shunt active power filter capability by adaptive neural filtering," IEEE Trans. Ind. Electron., vol. 55, no. 5, pp. 2093-2110, 2008.

[35] C. J. Gajanayake, D. M. Vilathgamuwa, P. C. Loh, R. Teodorescu, and F. Blaabjerg, "Z-source-inverter-based flexible distributed generation system solution for grid power quality improvement," IEEE Trans. Energy Convers., vol. 24, no. 3, pp. 695-704, 2009.

[36] R. I. Bojoi, L. R. Limongi, D. Roiu, and A. Tenconi, "Enhanced power quality control strategy for single-phase inverters in distributed generation systems," IEEE Trans. Power Electron., vol. 26, no. 3, pp. 798-806, 2011.

[37] J. He, Y. Li, F. Blaabjerg, and X. Wang, “Active harmonic filtering using current-controlled, grid-connected dg units with closed-loop power control," IEEE Trans. Power Electron., vol. 29, no. 2, pp. $642-$ 653, 2014.

[38] Y. W. Li and J. He, "Distribution system harmonic compensation methods: An overview of DG-interfacing inverters," IEEE Ind. Electron. Mag., vol. 8, no. 4, pp. 18-31, 2014.

[39] X. Yuan, W. Merk, H. Stemmler, and J. Allmeling, "Stationary-frame generalized integrators for current control of active power filters with zero steady-state error for current harmonics of concern under unbalanced and distorted operating conditions," IEEE Trans. Ind. Appl., vol. 38, no. 2, pp. 523-532, 2002.

[40] R. Teodorescu, F. Blaabjerg, U. Borup, and M. Liserre, "A new control structure for grid-connected LCL PV inverters with zero steadystate error and selective harmonic compensation," Ninet. Annu. IEEE Appl. Power Electron. Conf. Expo. APEC '04., 2004, vol. 1, no. C, pp. 580-586.

[41] C. Lascu, L. Asiminoaei, I. Boldea, and F. Blaabjerg, "High performance current controller for selective harmonic compensation in active power filters," IEEE Trans. Power Electron., vol. 22, no. 5, pp. 1826-1835, 2007.

[42] D. De and V. Ramanarayanan, "A proportional + multiresonant controller for three-phase four-wire high-frequency link inverter," IEEE Trans. Power Electron., vol. 25, no. 4, pp. 899-906, 2010.

[43] A. Kulkarni and V. John, "Mitigation of lower order harmonics in a grid-connected single-phase PV inverter," IEEE Trans. Power Electron., vol. 28, no. 11, pp. 5024-5037, 2013.

[44] P. Mattavelli and F. P. Marafao, "Repetitive-based control for selective harmonic compensation in active power filters," IEEE Trans. Ind. Electron., vol. 51, no. 5, pp. 1018-1024, 2004.

[45] R. Costa-Castelló, R. Griñó, and E. Fossas, “Odd-harmonic digital repetitive control of a single-phase current active filter," IEEE Trans. Power Electron., vol. 19, no. 4, pp. 1060-1068, 2004.

[46] J. M. Olm, G. a. Ramos, and R. Costa-Castelló, "Stability analysis of digital repetitive control systems under time-varying sampling period," IET Control Theory Appl., vol. 5, no. 1, p. 29, 2011.

[47] S. Jiang, D. Cao, Y. Li, J. Liu, and F. Z. Peng, "Low-THD, fast-transient, and cost-effective synchronous-frame repetitive controller for three-phase UPS inverters," IEEE Trans. Power Electron., vol. 27, no. 6, pp. 2994-3005, 2012.

[48] Q. Zeng and L. Chang, "An advanced SVPWM-based predictive current controller for three-phase inverters in distributed generation systems," IEEE Trans. Ind. Electron., vol. 55, no. 3, pp. 1235-1246, 2008.

[49] R. Shao, R. Wei, and L. Chang, "An improved current control algorithm for single-phase grid-connected inverters," 2014 IEEE 5th Int. Symp. Power Electron. Distrib. Gener. Syst. PEDG, 2014, pp. 1-6,

[50] G. H. Bode, P. C. Loh, M. J. Newman, and D. G. Holmes, "An improved robust predictive current regulation algorithm," Proc. Int. Conf. Power Electron. Drive Syst., 2003, vol. 2, no. 6, pp. 1058-1063.

[51] P. Mattavelli, "An improved deadbeat control for UPS using disturbance observers," IEEE Trans. Ind. Electron., vol. 52, no. 1, pp. 206-
$212,2005$.

[52] A. R. H. Mohomad, S. A. Saleh, L. Chang, R. Shao, and S. Xu, "Observer-based predictive current controller for grid-connected single-phase wind converter," Conf. Proc. - IEEE Appl. Power Electron. Conf. Expo. - APEC, 2017, pp. 2767-2772.

[53] P. Cortes, J. Rodriguez, C. Silva, and A. Flores, "Delay compensation in model predictive current control of a three-phase inverter," IEEE Trans. Ind. Electron., vol. 59, no. 2, pp. 1323-1325, 2012.

[54] J. R. Fischer, S. A. Gonzalez, M. A. Herran, M. G. Judewicz, and D. O. Carrica, "Calculation-delay tolerant predictive current controller for three-phase inverters," IEEE Trans. Ind. Informatics, vol. 10, no. 1, pp. 233-242, 2014.

[55] K. J. Lee, B. G. Park, R. Y. Kim, and D. S. Hyun, "Robust predictive current controller based on a disturbance estimator in a three-phase grid-connected inverter," IEEE Trans. Power Electron., vol. 27, no. 1, pp. 276-283, 2012.

[56] H. Mohomad, S. A. Saleh, and L. Chang, "Disturbance Estimator-Based Predictive Current Controller for Single-Phase Interconnected PV Systems," IEEE Trans. Ind. Appl., vol. 53, no. 5, pp. 42014209, 2017.

[57] Y. Yang, K. Zhou, and F. Blaabjerg, "Current harmonics from single-phase grid-connected inverters-examination and suppression," IEEE J. Emerg. Sel. Top. Power Electron., vol. 4, no. 1, pp. 221-233, 2016.

[58] M. Rashed, C. Klumpner, and G. Asher, "Repetitive and resonant control for a single-phase grid-connected hybrid cascaded multilevel converter," IEEE Trans. Power Electron., vol. 28, no. 5, pp. 22242234, 2013.

[59] W. Feng, K. Sun, Y. Guan, J. M. Guerrero, and X. Xiao, “Active power quality improvement strategy for grid -connected microgrid based on hierarchical control," IEEE Trans. Smart Grid, 2016.

[60] X. Wang, Y. W. Li, S. Member, and F. Blaabjerg, "Virtual-impedance-based control for voltage-source and current-source converters," vol. 30, no. 12, pp. 7019-7037, 2015.

[61] H. Akagi, H. Fujita, K. Wada, and S. Member, "A shunt active filter based on voltage detection for harmonic termination of a radial power distribution line," IEEE Trans. Ind. Appl., vol. 35, no. 3, pp. 638-645, 1999.

[62] H. Fujita and H. Akagi, "Voltage-regulation performance of a shunt active filter intended for installation on a power distribution system," IEEE Trans. POWER Electron., vol. 22, no. 3, pp. 1046-1053, 2007.

[63] J. He, Y. W. Li, and M. S. Munir, "A flexible harmonic control approach through voltage-controlled DG-grid interfacing converters," IEEE Trans. Ind. Electron., vol. 59, no. 1, pp. 444-455, 2012.

[64] X. Wang, F. Blaabjerg, and P. C. Loh, "Grid-current-feedback active damping for LCL resonance in grid-connected voltage source converters," IEEE Trans. Power Electron., vol. 31, no. 1, pp. 213-223, 2016.

[65] X. Wang, F. Blaabjerg, and P. C. Loh, "Virtual RC damping of 1cl -filtered voltage source harmonic compensation," IEEE Trans. Power Deliv., vol. 30, no. 9, pp. 4726-4737, 2015.

[66] Y. Song and F. Blaabjerg, "Wide frequency band active damping strategy for DFIG system high frequency resonance," IEEE Trans. Energy Convers., vol. 31, no. 4, pp. 1665-1675, 2016.

[67] H. M. Hasanien, “An adaptive control strategy for low voltage ride through capability enhancement of grid-connected photovoltaic power plants," IEEE Trans. Power Syst., vol. 31, no. 4, pp. 3230-3237, 2015.

[68] G. Ding et al., "Adaptive DC-link voltage control of two-stage photovoltaic inverter during low voltage ride-through operation," IEEE Trans. Power Electron., vol. 31, no. 6, pp. 4182-4194, 2016.

[69] S. A. Khajehoddin, M. Karimi-Ghartemani, A. Bakhshai, and P. Jain, "A power control method with simple structure and fast dynamic response for single-phase grid-connected DG systems," IEEE Trans. Power Electron., vol. 28, no. 1, pp. 221-233, 2013.

[70] F. Wu, D. Sun, L. Zhang, and J. Duan, "Influence of plugging dc offset estimation integrator in single-phase EPLL and alternative scheme to eliminate effect of input DC offset and harmonics," IEEE Trans. Ind. Electron., vol. 62, no. 8, pp. 4823-4831, 2015.

[71] M. Karimi-Ghartemani, "Linear and pseudolinear enhanced phasedlocked loop (EPLL) structures," IEEE Trans. Ind. Electron., vol. 61, no. 3, pp. 1464-1474, 2014.

[72] M. Ciobotaru, R. Teodorescu, and F. Blaabjerg, "A new single-phase 
PLL structure based on second order generalized integrator," PESC Rec. - IEEE Annu. Power Electron. Spec. Conf., 2006.

[73] P. Rodríguez, A. Luna, R. S. Muñoz-Aguilar, I. Etxeberria-Otadui, R. Teodorescu, and F. Blaabjerg, "A stationary reference frame grid synchronization system for three-phase grid-connected power converters under adverse grid conditions," IEEE Trans. Power Electron., vol. 27, no. 1, pp. 99-112, 2012.

[74] H. Yi, X. Wang, F. Blaabjerg, and F. Zhuo, "Impedance analysis of SOGI-FLL-based grid synchronization," IEEE Trans. Power Electron., vol. 32, no. 10, pp. 7409-7413, 2017.

[75] L. Hadjidemetriou, E. Kyriakides, Y. Yang, and F. Blaabjerg, “A synchronization method for single-phase grid-tied inverters," IEEE Trans. Power Electron., vol. 31, no. 3, pp. 2139-2149, 2016.

[76] L. Hadjidemetriou, Y. Yang, E. Kyriakides, and F. Blaabjerg, “A synchronization scheme for single-phase grid-tied inverters under harmonic distortion and grid disturbances," IEEE Trans. Power Electron., vol. 32, no. 4, pp. 2784-2793, 2017.

[77] M. Karimi-Ghartemani, S. A. Khajehoddin, P. K. Jain, A. Bakhshai, and M. Mojiri, "Addressing DC component in pll and notch filter algorithms," IEEE Trans. Power Electron., vol. 27, no. 1, pp. 78-86, 2012.

[78] J. Matas, M. Castilla, J. Miret, L. Garcia De Vicuna, and R. Guzman, "An adaptive prefiltering method to improve the speed/accuracy tradeoff of voltage sequence detection methods under adverse grid conditions," IEEE Trans. Ind. Electron., vol. 61, no. 5, pp. 2139-2151, 2014.

[79] W. Li, X. Ruan, C. Bao, D. Pan, and X. Wang, "Grid synchronization systems of three-phase grid-connected power converters: A complex-vector-filter perspective," IEEE Trans. Ind. Electron., vol. 61, no. 4, pp. 1855-1870, 2014.

[80] S. Golestan, S. Y. Mousazadeh, J. M. Guerrero, and J. C. Vasquez, "A critical examination of frequency-fixed second-order generalized integrator-based phase-locked loops," IEEE Trans. Power Electron., vol. 32, no. 9, pp. 6666-6672, 2017

[81] Z. Xin, X. Wang, Z. Qin, M. Lu, P. C. Loh, and F. Blaabjerg, “An improved second-order generalized integrator based quadrature signal generator," IEEE Trans. Power Electron., vol. 31, no. 12, pp. 80688073, 2016.

[82] Z. zhang, Y. yang, F. Blaabjerg, "Challenges to grid synchronization of single-phase grid-connected inverters in zero-voltage ride-through operation," 2016 IEEE 2nd Annu. South. Power Electron. Conf., pp. $1-6,2016$.

[83] Y. S. Wu, C. H. Chang, Y. M. Chen, C. S. Cheng, C. W. Liu, and Y. R. Chang, "The current control of PV inverter for low voltage ride through," 15th Int. Power Electron. Motion Control Conf. Expo. EPEPEMC 2012 ECCE Eur., pp. 2-7, 2012.

[84] Y. Wu, C. Chang, Y. Chen, C. Liu, and Y. Chang, "A current control strategy for three-phase pv power system with low-voltage ridethrough," 9th IET Int. Conf. Adv. Power Syst. Control. Oper. Manag., 2012 pp. 1-6.

[85] Y. Yang, H. Wang, and F. Blaabjerg, "Reactive power injection strategies for single-phase photovoltaic systems considering grid requirements," IEEE Trans. Ind. Appl., vol. 50, no. 6, pp. 4065-4076, 2014.

[86] H. Tian, F. Gao, G. He, and G. Li, "Low voltage ride through of twostage photovoltaic inverter with enhanced operational performance," Conf. Proc. - IEEE Appl. Power Electron. Conf. Expo. - APEC, 2012, pp. 1995-2001

[87] C. Y. Tang, Y. T. Chen, and Y. M. Chen, "PV power system with multi-mode operation and low-voltage ride-through capability," IEEE Trans. Ind. Electron., vol. 62, no. 12, pp. 7524-7533, 2015.

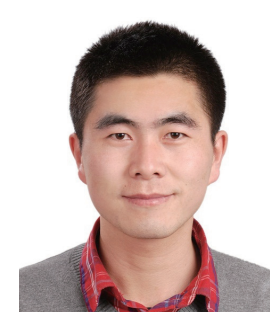

Xin Zhao received the B.E., M.E., and Ph.D. degrees in electrical engineering from Beijing Jiaotong University, Beijing, China, in 2008, 2010 and 2014, respectively.

He was a Postdoctoral Research Fellow at Beijing Jiaotong University from 2014 to 2016, and he visited University of Alberta for one year during this period. He is currently with the Department of Electrical and Computer Engineering at University of New Brunswick. His main research interests are smart inverters, microgrids, and ACmotor drives.

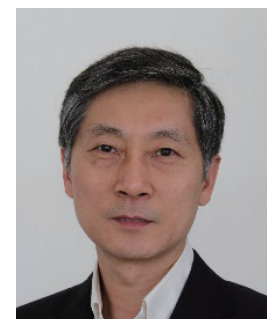

Liuchen Chang received B.S.E.E. from Northern Jiaotong University in 1982, M.Sc. from China Academy of Railway Sciences in 1984, and Ph.D. from Queen' University in 1991. He joined the University of New Brunswick in 1992 and is a professor in Electrical and Computer Engineering. He was the NSERC Chair in Environmental Design Engineering during 2001-2007, and was the Principal Investigator of Canadian Wind Energy Strategic Network (WESNet) during 2008-2014. He chaired the Sustainable Energy System Technical Committee (20112015 ) and is a vice president of the IEEE Power Electronics Society.

Dr. Chang was a recipient of CanWEA R.J. Templin Award in 2010 for his contribution in the development of wind energy technologies, and the Innovation Award for Excellence in Applied Research in New Brunswick in 2016 for his contributions in smart grid and renewable energy technologies. $\mathrm{He}$ is a fellow of Canadian Academy of Engineering (FCAE). He has published more than 330 refereed papers in journals and conference proceedings. Dr. Chang has focused on research, development, demonstration and deployment of renewable energy based distributed generation systems and direct load control systems.

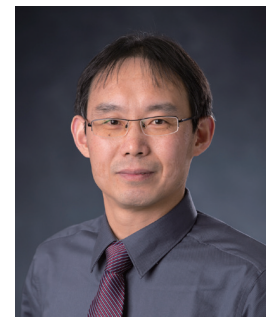

Riming Shao received the B.Sc.E.E. in 1994 and M.Sc. in 1997 from Tongji University, Shanghai, China; and the Ph.D. in 2010 from the University of New Brunswick, Fredericton, Canada. He is currently a Research Associate with the Emera and NB Power Research Centre for Smart Grid Technologies at the University of New Brunswick. His research interests include smart grids, power converters, renewable energy systems, and distributed power generation systems. Dr. Shao is a registered professional engineer of APEGNB, Canada.

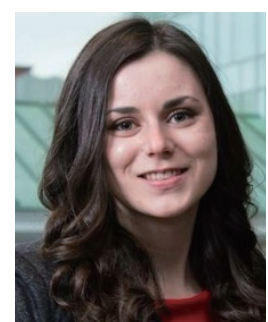

Katelin Spence received a B.Sc. EE. in 2016 from The University of New Brunswick, Fredericton, Canada. She is now pursuing a M. Sc. degree in Electrical Engineering, also at the University of New Brunswick. Her research interest are renewable energy, power electronics, distributed generation, and energy storage. 